\title{
Gargle Dosage Form
}

National Cancer Institute

\section{Source}

National Cancer Institute. Gargle Dosage Form. NCI Thesaurus. Code C78748.

A solution or suspension taken orally and moved around the back of the throat by tilting the head back and forcing air from the lungs through the solution. Unless specifically directed, the solution is expelled and not swallowed. 